\title{
Knowledge as Power on the Internet
}

\author{
Zelinna Pablo ${ }^{1}$ and Cynthia Hardy ${ }^{2}$ \\ ${ }^{1}$ De La Salle University College of Computer Studies \\ 2401 Taft Avenue, Manila, Philippines \\ zelinna.pablo@dlsu.edu.ph \\ ${ }^{2}$ Department of Management and Marketing \\ The University of Melbourne \\ 198 Berkeley Street, Carlton, Victoria, Australia \\ chardy@unimelb.edu.au
}

\begin{abstract}
In this study we explore how knowledge produced on the Internet can reflect objectivist or subjectivist views. These different views shape participation dynamics in the knowledge production process in ways that are bound up with power. To explore these issues, we conducted a comparative case study of websites under the Development Gateway, an initiative launched by the World Bank in 2001. We examined how objective knowledge is associated with tightly controlled processes of knowledge production dominated by an elite that limits electronic participation, while subjective knowledge is associated with processes characterized by more inclusiveness, polyvocality and (qualified) egalitarianism.
\end{abstract}

Keywords: knowledge, power, discourse, Development Gateway.

\section{Introduction}

For some observers, the Internet is a revolutionary technological development that offers the ability to liberate the production of knowledge from Orwellian constraints. It acts as a democratizing force that facilitates participation, increases access to information, promotes open debate, encourages multiple perspectives [23], and offers the promise of a Habermasian cyber-café [13]. Part of this emancipation involves large numbers of "ordinary" people around the world who can now participate electronically in the production of knowledge that affects their lives. Under this view of technology, it has been argued that the Internet has undoubtedly facilitated the collective production of knowledge [26] as, perhaps, best exemplified by Wikipedia - a rapidly growing, collaborative website fuelled by the contributions of some millions of people around the world. Such a view of collective knowledge production is consistent with what has been called "subjectivist" perspectives of knowledge, which emphasize the participatory, constructionist processes whereby knowledge is generated using a bottom-up approach, thus suggesting a decoupling of knowledge from the strictures of control. There are, however, others who uphold more dystopian perspectives of the Internet, suggesting such new technologies provide governments and business with opportunities for enhanced control and surveillance [18]. Under such views knowledge and information continue to be produced and/ or controlled by an elite. This leads to arrangements that 
sustain traditional objectivist accounts of knowledge, which emphasize the view that knowledge creation involves limited participation. Under this view, knowledge is thus produced and dispensed in a top-down manner.

However, neither traditional objectivist nor more recent subjectivist accounts of knowledge production place much emphasis on the role of power in knowledge production processes [5]. As a result, we know relatively little about whether knowledge produced on the Internet reflects objectivist or subjective views, how participatory these two modes of knowledge production are, and how these different processes of knowledge production are bound up with power. To explore these issues, therefore, we conducted a case study of the Development Gateway, a global knowledge sharing web-based initiative launched by the World Bank in 2001. By examining the discursive resources on the portal (instead of simply focusing on the presence or absence of features like news items and discussion fora), we are in a position to learn more about different ways by which knowledge is produced, how knowledge production processes are shaped, and how these processes have diverging outcomes in terms of power positions for various stakeholders.

\section{The Production of Knowledge}

Researchers have identified different approaches to, and conceptualizations of, knowledge [2]. Von Krogh [34] distinguishes between cognitivist and constructionist views of knowledge; Wasko and Faraj [36] differentiate between knowledge as a private and as a public good; and Orlikowsi and Baroudi [25] contrast positivist and interpretivist approaches. In this section, we focus primarily on the distinction between "objective" and "subjective" knowledge.

In particular, what might loosely be described as "objectivist" views of knowledge have been contrasted with knowledge described as "subjective". Knowledge under these two views can be contrasted in five ways: applicability, coherence, articulation, instrumentality, and resulting interactions between knowledge producers and consumers. Universal knowledge in this case is seen to be universally applicable [19], coheres systematically into a single monolithic body [21], is articulated in scientific (often technical) terms [22], and is mobilized for problem solving, prediction, and the control of both natural and social phenomena [1]. Because knowledge is technical, scientific, and often costly to produce, its production is often limited to an elite group of experts who create and disseminate it to consumers [20]. In contrast, subjective knowledge is context-specific [19]; does not converge into a single and coherent body [20]; exists in practices and language and can be articulated in "non-scientific" and tacit forms such as experience, tradition, or intuition [17]; and can be purposeful, for example for understanding, but is not exclusively mobilized for problem-solving and control [25]. Because of its nature, subjectivist knowledge is produced as a result of sense-making among actors in different contexts, for example in communities of practice, and knowledge production processes are not limited to an elite group of experts [3] [15].

One limitation about this dichotomy is that power does not feature greatly in either of the above two perspectives. In the case of objective knowledge, power is repudiated as anything that smacks of "emotive involvement and subjectivity" [16]; while 
Contu and Willmott [5] argue that even constructionist approaches fail to acknowledge the wider societal and organizational power relations that shape the context within which knowledge is socially constructed. Orlikowski \& Baroudi [25] thus emphasize the importance of a third approach, which they call critical. Like the subjective approach, a critical approach acknowledges that knowledge is historically and socially located; but it goes considerably further in drawing attention to the way in which power shapes the production of knowledge, including the inequities and inequalities that exist in relation to the ability to produce knowledge, as well as the way in which the constructive effects of knowledge can have political consequences. Using a critical approach, one can achieve a more explicit recognition of the ways in which knowledge and power are linked. For example, Roberts [30] argues that communities of practice consist of individuals with different standing in terms of experience, expertise, age, personality and authority, and the knowledge that is produced reflects and reinforces existing power structures.

We therefore seek to explore how knowledge and power are linked as knowledge is produced on the Internet. The Internet has been seen as a potentially emancipatory force that allows people to circumvent traditional barriers to accessing and producing knowledge in ways that challenge authority [35], decentralize decision making [9], and facilitate self organizing communities [31]. More recently, however, many researchers have become skeptical that with knowledge comes emancipation. Foucault's work in particular has brought about a greater understanding of how power and knowledge are inseparable, having argued that "the exercise of power perpetually creates knowledge and, conversely, knowledge constantly induces effects of power" [12].

According to this view, therefore, knowledge can never be neutral. It is integral to the operation of power [33]. Power produces individuals who are rendered knowable in particular ways through particular forms of knowledge [6]. The question, therefore, is not "whether the knowledge that is generated is objective or subjective ... [but] what is involved in rendering an arena or individuals knowable: What are the processes by which they become known ... What are their effects?" [33]. Our interest, therefore, is to empirically explore the links between knowledge and power by analyzing not just the type of knowledge that comes to be constructed on the Internet, but also their effects in terms of participation of people in knowledge production processes, as well as the power positions that result from these dynamics.

\section{Methods}

Our study involves the comparison of 29 Web portals that formed part of the Development Gateway - a multimillion-dollar initiative launched in 2000 by the World Bank in line with its mission to "fight poverty and improve living standards of people in the developing world" [37]. The Development Gateway was envisioned to be a global portal for knowledge creation and knowledge sharing. It was built on participatory models and intended to be the premiere point of entry for finding Web-based knowledge on poverty and sustainable development, such as reports, articles, statistics, discussion groups, transactions, and policy analyses, which could be used by a variety of stakeholders - from large banks to grassroots organizations to individual users. In addition to the main website there are also 28 country-based versions, known 
as Country Gateways. These web portals were all set up under the same mandate i.e., to use ICT to help reduce poverty [8].

We selected this research site for three main reasons. First, the production of knowledge is integral to the Development Gateway and the Country Gateways. The main purpose of the Development Gateway, for example, was to "improve people's lives in developing countries by building partnerships and information systems that provide access to knowledge for development", with one major goal being to "increase knowledge sharing" [DG2005-06].

The second reason for selecting this site was it seemed likely that we would be able to compare the implications of different models of knowledge production. On the one hand, the World Bank Report on Knowledge for Development [38] employed language reminiscent of an objectivist view of knowledge [20], when it opened with:

"Knowledge is like light. Weightless and intangible, it can easily travel the world, enlightening the lives of people everywhere ... Knowledge is often costly to create and that is why much of it is created in industrial countries. But developing countries can acquire knowledge overseas as well as create their own at home" [38]

In contrast, other documents authored by the World Bank stressed a view of knowledge more consistent with the subjective view by emphasizing building knowledge through partnerships and creating communities of practice that would facilitate knowledge sharing and collective problem solving [37]. In this way, the research setting offered the prospects of examining both approaches to knowledge and any tensions between them.

Third, the Country Gateways present a compelling research site for a multiple case study design [11] - they were all set up under the same mandate by the World Bank; received funding from the same World Bank grant; and are subject to the same guidelines. In this way, the research site constitutes a natural experiment, in which the 28 Country Gateways that use English, as well as the Development Gateway itself, can be systematically compared [8].

Data collection commenced in June and July of 2005 by downloading the home pages of 28 Country Gateways, as well as the original Development Gateway, in MHTML format. The home pages of all the portals were downloaded again between September 2005 and January 2006, together with subordinate pages one level deeper than the home pages i.e., each page immediately linked to every clickable item on the home page.

We began our analysis by creating a list of all the individual features that could be identified from the 29 home pages. A feature is a group of website elements held together by an explicit or implicit frame, such as white space or logical clustering. For example, a "news article" may be a feature made up of multiple elements: words, photos, and a comment box, and all these are implicitly linked together by virtue of location and content. Another feature might be the box containing a special report, which might contains three elements: an icon, a description of the special report, and a link to where the report can be downloaded, all bound together by an explicit frame.

Our initial analysis involved attempts to map the presence or absence of certain features with specific types of knowledge (for example, centrally-produced news articles suggested objectivist views, discussion fora suggested subjectivist views). This was in line with literature that suggests that certain website features can be mobilized to 
achieve certain levels of participation: for example, a website aimed at educating users requires the use of a discussion forum; one that aims at input probing calls for web comment forms [29]. However, a deeper examination of the portals showed that a single feature was often endowed with too much complexity to be used as the most basic unit of analysis. For example, we found that a discussion forum feature, which some have equated with subjectivist and participative forms of knowledge, was often a convergence of many elements: words, visuals, rules, roles assigned to parties, and these elements could send out different signals. We found cases of discussion fora wherein words and headings were welcoming and inclusive, yet rules and roles were so restrictive and confining that only one expert participant could give input, and all other participants were restricted to "silent" reading [26]. Cases such as these would call into question the assumption that interactive mechanisms like a "discussion forum" or "chat" can automatically be equated with participative forms of knowledge.

Thus instead of analyzing the contents of websites using features as a unit of analysis, we made use of techniques that allowed us to "disassemble" websites into finer units, in this case discourses. Discourses include written language, spoken language, cultural artifacts, or visual representations [15]. On a website, these discourses took the form of words, visuals, and interactivity elements. The ways that these discourses are mobilized are referred to as "discursive strategies." Our analysis of these resources is a methodology called "discourse analysis", which involves the systematic qualitative investigations of such "texts" i.e., the examination of what these texts are, how they relate to other texts, and what their meaning is.

Our analysis took place in three stages. First, we created a table for each portal in which we analyzed the discourses present on their homepages, in order to generate detailed interpretations. To analyze words on the homepage, we drew from traditional discourse analysis [28] and journalism [24] and analyzed the written text according to four categories (a single category overarches multiple questions): the genre of resources; sources, speakers, and authors; topicalization; and tone. This enabled us to detect characteristics such as the use of detached, scientific, "objective" language as opposed to more emotional or personal tones. To analyze visual resources, we drew from marketing and visual design [16] to analyze the website using another six categories: the organization of the webpage (e.g., streamlined, simple layout); composition (e.g., many elements or few); modality (saturation, differentiation) and color scheme; salient elements; nature of visual resources; and the content of visual resources. This enabled us to discern characteristics such as whether or not real people were being shown and portrayed in certain ways, or if detached, clinical icons were being used instead. We also analyzed interactivity according to nine categories, drawing from the field of information systems [14] [32] to examine features such as ease of access to site; spread of site; use of tools like chat or bulletin boards; use of forms like dropdown menus or radio buttons; transactional capabilities (type, depth, rules and assumptions); language capabilities; linking; and functionalities that establish an item as salient. This enabled us to discern if a website was open to input and interaction, or if it was primarily pushing material out at a "passive" audience.

Second, we categorized these interpretations using categories from knowledge theories: applicability, coherence, articulation, instrumentality, and relationship between producers and consumers of knowledge, discussed earlier. This allowed us to aggregate 
our interpretations for each portal to see if an overall pattern could be discerned that indicated the dominance of one or other of the two views/forms of knowledge.

Finally, in the last stages of analysis, we selected two cases as "ideal types" - one that conformed closely to the ideal type associated with the view of knowledge as objective - the Development Gateway - and one that conformed closely to the ideal type associated with the view of knowledge as situated - the Croatia Country Gateway. These two selected portals are value adding for theoretical development in that they are, to use Flyvberg's [11] terminology, prototypical cases. We then explored these two cases in more detail to show in greater depth the implications of these two different views of knowledge. Specifically, we examined the power effects of these web portals, in particular the way in which they constructed different power positions; most notably the producers, legitimators and consumers of knowledge. In doing so we addressed the following questions: (1) What are the characteristics and knowledge production processes associated with objective and subjective knowledge on webbased portals? and (2) What are the power dynamics associated with stakeholders on portals that reflect different views of knowledge?

\section{Findings and Discussion}

We selected two portals which show contrasting patterns in the way knowledge is produced and disseminated which, broadly speaking, can be characterized as objective and subjective. The Development Gateway [8] presents knowledge that is consistent with the objective view, while the Croatia Country Gateway [7] shows knowledge that is consistent with the subjective view. These views in turn have implications on interactions and power positions of stakeholders of these portals.

\subsection{Knowledge and Power in the Development Gateway}

In earlier work [27] we investigated the Development Gateway and concluded that it conformed to characteristics associated with objectivist forms of knowledge. We summarize findings here in order to set up the comparative case study. Under "Knowledge" we explore the categories of applicability, coherence, articulation, and instrumentality. We explore the fifth category, interactions between producers and consumers, in the subsequent sub-section, "Interactions and Power".

Knowledge in the Development Gateway. First, an analysis of the website [DG2005$01]^{1}$ indicated that knowledge was presented in universally applicable terms. For example, the home page showed an emphasis on global rather than country-specific matters. On this main page, the "Special Report" focused on the Millennium Development Goals, which are global indicators dealing with poverty eradication. The "Featured Book" focused on the macro phenomenon of inequality between countries. The Aid Harmonization and Human Development Reports, as well as the databases and statistics, were not focused on a particular country although they did provide a regional basis for the data. Knowledge about specific countries was more short-lived - highlighted only for a limited period. There are also claims of universality in the form of broad

\footnotetext{
${ }^{1}$ A reference in brackets refers to a page that was downloaded as part of data analysis.
} 
invitations ("All who are interested in ICT for Development are welcome to join us... This site is aimed to help all of you!") [DG2006-08].

Second, knowledge was presented as a coherent, comprehensive, detailed and systematic taxonomical scheme. The home page divided information 28 different development areas, originally called "topics" and, subsequently, "communities" [DG2006-02]. The topics were diverse, ranging from nanotechnology to indigenous issues to microfinance. An examination of the topic ICT for Development showed that it was further broken down into 47 key issues linking ICT to e-commerce; poverty; disabled persons; and arts and culture. The ICT for Development topic contained a total if 8991 resources [DG2006-08], more than the total number of resources found on the Australia Development Gateway.

Third, knowledge was articulated in highly technical terms, making use of extensive jargon and employing the specialized language of development. The homepage's list of its five Most Popular Items of the Week included UNCTAD's World Investment Report, which "presents the latest trends in foreign direct investment (FDI) and explores the internationalization of research and development by transnational corporations (TNCs) along with the development implications of this phenomenon". A second popular item is a book that aims to teach readers to "employ a uniform, coherent, and timetested methodology for identifying and quantifying the impact of various disasters on the affected social, economic and environmental sectors" [DG2006-01]. The portal thus uses the language of experts, not laymen.

Fourth, much of the knowledge on the Development Gateway was constructed to serve the purpose of systematic problem solving. Problems published include "internet access and staff capacity [being] key constraints in SMEs seeking to grow", "donor support for pure infrastructure projects [having] dropped dramatically"; and "access to and benefits to ICT [still being] limited to a subset of the population" [DG2006-21]. Solutions included a new fund for rural innovation in India; an online community to link 100,000 youth around the world, and how a new Iraqi media institute has been set up to facilitate war and peace reporting [DG2006-08].

As a result of the type of knowledge that is privileged on the portal, knowledge production processes take on a very distinct shape. Knowledge production is controlled from the very start of the contribution process by a number of filters that restrict access into the arena: before a person can contribute, one must sign up to be a member, then find the appropriate topic under which one's work can be published, and then submit one's work to designated people who will still screen the quality of one's work. The ICT for Development community, for example, was overseen by three "guides", 51 "advisors", two "coordinators", one "volunteer", and 27 "cooperating organizations"; in its discussion forum it is noted that "The Development Gateway may edit or remove your comments" [DG2006-07].

The hurdles that one must go through before one can have a voice in the arena have been taken by some to be excessive. For example, on May 29, 2001, a potential contributor wrote, "Great site, please add a community on anti corruption, also I tried 4 times to add my article under law and justice but was not successful, although I am quite technical. Thanks." [DG2006-42]. This statement indicates the presence of filters in the form of technical difficulties (tricky even for one with technical skill, as indicated) as well as taxonomical filters due to the absence of a desired subject. Upon 
being told that the Anti-Corruption site requested was being constructed off-line under the management of Transparency International, the same contributor responded

"I work with Transparency International that is why I told you to add the category. I told you, and that was when it was done. Stop trying to discourage individuals just because you do not know who they are connected with.” [DG2006-42]

Hence the comment would suggest another filter, a lack of affiliation. A third message posted by this same contributor complained about how guides appeared to be privileging their own postings, saying that they put their names on their own postings but did not label members', hence "... it does not look like a knowledge sharing database but a way for guides to blow thier [sic] own horn." [DG2006-43]. This would indicate a screening mechanism, arguably one for quality control, but which has also been interpreted to favor appointed topic guides and like-minded people with a certain definition of what constitutes a good article. Certain individuals thus decided which material was ultimately published and which material was deemed "inappropriate". Interestingly, in earlier work it was also found that different strategies were being (consciously or unconsciously) employed to "keep out", or at least modify, indigenous forms of knowledge, in favor of more scientific forms [27].

Interactions and Power in the Development Gateway. Our findings show that three sets of stakeholders appear to have the strongest power positions in the knowledge production process. First, international organizations (the World Bank, IMF, as well as organizations or individuals who are capable of producing specialized, technical, Western-type development knowledge) are privileged, being the so-called "experts" who populate the communities. Second, the Development Gateway Foundation is also privileged because it plays a dual role of publisher and author of materials. Third, community guides, advisors, coordinators, volunteers, and cooperating organizations are given significant influence. They have decision-making power, and they are further legitimated through their published curriculum vitas. In contrast, people who are non-specialists, limited to layman's language, are non-technical English speakers, as well as authors and users "indigenous" materials on development, will also not be in a strong position to contribute.

The type of knowledge, the nature of key players, and the dynamics of interaction in the knowledge production process can be interlocked into a power pattern that legitimates only a certain type of knowledge, and leaves out others. By virtue of size, international status, and reputation, the website owner (first the World Bank, then the Development Gateway) is endowed with a certain degree of credibility. It publishes mostly robust, technical, largely economic, Western information on a portal that comes across as an expert. By virtue of authorship, the nature of contents ("credible" statistics and scientific reports), and the packaging of contents on the portal (detached, jargon-laden, heavily screened), the materials also become endowed with a certain degree of credibility. Mechanisms are put in place to maintain certain levels of quality. Thus we see the beginnings of a cyclical process of knowledge legitimation, in this case the ongoing construction and reconstruction of a body of knowledge that is technical, scientific, objective, and applicable anywhere, by selected players. 


\subsection{Knowledge and Power in the Croatia Country Gateway}

Knowledge in the Croatia Country Gateway. The Croatia Country Gateway was selected as the prototypical website associated with subjectivist characteristics, and hence an interesting contrast to the Development Gateway. First, the applicability of knowledge is more focused and context-specific. There are global or international resources ("Global security attacks up 36\%"; "UNDP launches Human Development Report 2003"), but many resources provide a more specific geographic context, e.g., the European Union ("European Commission proposes new e-government initiative"), Eastern European resources ("Eastern Europe is overtaking the west in use of IT within government, says new research"), and Croatia ("Nominate best Croatian econtent for World Summit award") [CROA2005-01].

Second, knowledge was not presented as a coherent body of resources classifiable into strict taxonomies of topics. The Croatia Country Gateway did not even list topics that it specialized in, and overall the home page indicated an absence of a unifying theme. There was an article "Baring It All For Breast Cancer"; a banner saying "Help Asia" with a child who is a victim of the December 26, 2004 tsunami; a letter written by an individual named Branko Mijic to George W. Bush about the war on Iraq; and a news article from Wired! magazine about research on helping people with missing arms and legs "grow your own limbs". The diversity of these articles served to create an unstructured approach as to which articles could be incorporated into a loosely defined "smorgasbord" of resources. Further, the portal does not appear to carve out spaces for neatly organized topics; instead it creates spaces for different users. Spaces are allocated to the editor (who gets his own little domain instead of the run of the entire page), syndicators, different types of users like business and government. Based on our analysis, rather than a well-integrated, carefully pieced together picture of development solutions, the objective of the website appears to be giving "voice" to different participants, regardless of characteristics [CROA2005-01].

Third, knowledge on the Croatia Country Gateway is articulated in catchy and accessible form. The subjects, such as new games and downloadable material, can be said to be of general interest. This is consistent with the subjective view of knowledge: that there are many forms of legitimate knowledge, some of which go beyond the technical and scientific, and which may in fact be classified as mundane. As mentioned earlier, headlines such as "Baring It All for Breast Cancer", "Eye-Popping Streaming Film Debuts", and "Journey to the End of the Night" [CROA2005-01] appear to be framed in provocative ways which could presumably arouse an ordinary person's interest. This leads to a fourth point - it suggests also suggest a departure from purer forms of instrumentality where knowledge is clearly linked to some useful purpose like solving a problem, focusing instead on purposes such as simple entertainment.

As a result, there are a number of processes that are left loose and flexible in the Croatia Development Gateway, allowing knowledge production to be inclusive. First, there is no strict agenda or fixed list of topics that could potentially lock out certain contributions. Second, barriers to entry into the arena are lowered: the editor is confined to a specific space; language is made accessible; immediate publication is hinted at. Finally, the quality of the discussion is not strictly regulated, as shown by the diversity and novelty of specific articles. 
Interactions and Power in the Croatia Country Gateway. Interactions in the Croatia Country Gateway are characterized by greater participation, and hence power is seen to be dispersed across a broad base of stakeholders rather than concentrated in the hands of an elite. We can see this in a number of ways, some of which have already been mentioned. The portal makes a broad invitation to almost anyone, saying "We promote independence and creativity, innovation and openness and we welcome unsolicited papers, articles, columns...Write to us - so you can start writing for us..." There is no explicit indication that it caters only to a particular group such Croatians (that is, the site is not even limited to Croatian visitors, as there is only one small reference to Croatia in the entire homepage) [CROA2005-01]. The reference to "unsolicited" work makes an even stronger statement for its openness. In this context, even the seemingly "most powerful" players get interrogated (there are criticisms of the World Bank, the US government, and George W. Bush). Hence the portal comes across as an environment available to just about anyone, and a domain for bringing up any subject.

The Croatia Country Gateway's "openness" must, however, be qualified: it is open, but still does not ensure that the playing field is completely equal for all players. This portal demonstrates what has been suggested by Marglin [19]: that a community can be pluralistic without being completely egalitarian. Some parties still have more say than others. The dominance of articles on information technology could lead one to suggest that the portal is not completely open taxonomically to non-IT articles. Furthermore, because of the nature of the topic, the language can come across as quite jargon-laden: terms like "Blu-ray", "Phish", "EV1 servers", "Router Worm" might be seen as intimidating to the layman, hence screening out non-IT users and making the portal an arena for computer science aficionados. Also, a look at the sources of many of the materials indicates that they are of Western origin: Slashdot is Michigan-based; Reuters' main offices are in London and New York; Netcraft is based in England. Large international organizations of the development community are also heavily drawn from. What is worth noting, though, is that these "privileged" sources are still just a few of many voices. They are present, but do not dominate. Further, some of these sources are not immune from criticism (for example, the World Bank is simultaneously portrayed as a sponsor and criticized on the homepage). These arguments would support the view that Croatia Country Gateway is an open, pluralistic environment, albeit with traces of hierarchy.

\section{Conclusions}

In addressing the two research questions we have made three contributions. First, we have contributed to current understandings of electronic participation by showing how views of knowledge can impact on participation dynamics on the Internet. The Internet is widely perceived as a tool that facilitates participation, but our research has shown specific ways that participation can be constrained as a result of assumptions about what legitimate knowledge is and who should be allowed to create it in an electronic arena. Second, we have shown how diverging assumptions embodied by these two types of knowledge shape interactions and knowledge production processes, thus resulting in certain power positions for different stakeholders. In showing this we 
have contributed to understandings of how knowledge and power are linked. Third, we have demonstrated the value of a discourse analytic approach to analyzing websites, showing how dissecting websites into more finely tuned texts can enable researchers to discern patterns that may not emerge from an analysis of features.

\section{References}

1. Addleson, M.: Resolving the Spirit and Substance of Organizational Learning. Journal of Organizational Change Management 9(1), 32-41 (1996)

2. Blackler, F.: Knowledge, Knowledge Work and Organizations: An Overview and Interpretation. Organizational Behavior 16(6), 1021-1046 (1995)

3. Boland, R.J., Tenkasi, R.V.: Perspective Making and Perspective Taking in Communities of Knowing. Organization Science 6(4), 350-372 (1995)

4. Cohen, D., Laporte, B.: The Evolution of the Knowledge Bank. KM Magazine (March 2004)

5. Contu, A., Willmott, H.: Re-Embedding Situatedness: The Importance of Power Relations in Learning Theory. Organization Science 14(3), 283-296 (2003)

6. Covaleski, M.A., Dirsmith, M.W., Heian, J.B.: The Calculated and the Avowed: Techniques of Discipline and Struggles Over Identity in Big Six Public Accounting Firms. Administrative Science Quarterly 43(2), 293-327 (1998)

7. Croatia Country Gateway, http: //www. gateway.hr/

8. Development Gateway, http: / / www . developmentgateway . org

9. Dewett, T., Jones, G.R.: The role of Information Technology in the Organization: A Review, Model, Assessment. Journal of Management 27, 313-346 (2001)

10. Eisenhardt, K.M.: Building Theories From Case Study Research. Academy of Management Review 14(4), 532-550 (1989)

11. Flyvbjerg, B.: Five Misunderstandings About Case-Study Research. In: Seale, C., Gobo, G., Gubrium, J.F., Silverman, D. (eds.) Qualitative Research Practice, pp. 420-434. SAGE Publications, London (2004)

12. Foucault, M.: Power/Knowledge: Selected Interviews and Other Writings 1972-1977. In: Gordon, C. (ed.). Pantheon, New York (1980)

13. Hall, M.: Virtual Colonization. Journal of Material Culture 4, 39-55

14. Hart-Davis, G.: HTML QuickSteps. McGraw-Hill, California (2005)

15. Hardy, C.: Researching Organizational Discourse. International Studies of Management and Organization 31(3), 25-47 (2001)

16. Kress, G., Van Leeuwen, T.: Reading Images: The Grammar of Visual Design. Routledge, London (1996)

17. Lave, J., Wenger, E.: Situated Learning: Legitimate Peripheral Participation. Cambridge University Press, Cambridge (1991)

18. Lyon, D.: Surveillance in Cyberspace: The Internet, Personal Data, and Social Control. Queen's Quarterly 109(3), 345-356 (2002)

19. Marglin, S.A.: Losing Touch: The Cultural Conditions of Worker Accommodation and Resistance. In: Marglin, F.A., Marglin, S.A. (eds.) Dominating Knowledge: Development, Culture, and Resistance, pp. 217-282. Clarendon Press, Oxford (1990)

20. Mehta, L.: The World Bank and Its Emerging Knowledge Empire. Human Organization 60(2), 189-196 (2001)

21. Nonaka, I.: A Dynamic Theory of Organizational Knowledge Creation. Organization Science 5(1), 14-37 (1994) 
22. Nonaka, I., Takeuchi, H.: The Knowledge-Creating Company. Oxford University Press, New York (1995)

23. Nye Jr., J.S., Zelikow, P.D., King, D.C.: Why Americans Mistrust Government. Harvard University Press, Cambridge (1997)

24. Olasky, M.: Prodigal Press: The Anti-Christian Bias of the American News Media. Crossway Books, Illinois (1998)

25. Orlikowski, W., Baroudi, J.J.: Studying Information Technology in Organizations: Research Approaches and Assumptions. Information Systems Research 2(1), 1-28 (1991)

26. Pablo, Z., Hardy, C.: Merging, Masquerading, and Morphing: Metaphors and the World Wide Wed. Journal of Organization Studies 30(8), 821-843 (2009)

27. Pablo, Z.: The Exclusiveness of he Universal: A Case Study of the Discursive Construction of Knowledge on the Internet. Philippine Computing Journal 5(2), 50-59 (2010)

28. Paltridge, B.: Making Sense of Discourse Analysis. Merino Lithographics, Brisbane (2000)

29. Phang, C.W., Kankanhalli, A.: A Framework of ICT Exploitation for E-Participation Initiatives. Communications of ACM 51(12), 128-132 (2008)

30. Roberts, J.: Limits to Communities of Practice. Journal of Management Studies 43(3), 623-639 (2006)

31. Ross, D.A.R.: Backstage with the Knowledge Boys and Girls: Goffman and Distributed Agency in an Organic Online Community. Organization Studies 28(3), 307-325 (2007)

32. Singh, N., Zhao, H., Hu, X.: Cultural Adaptation on the Web: A Study of American Companies' Domestic and Chinese Websites. Journal of Global Information Management 11(3), 63-80 (2003)

33. Townley, B.: Foucault, Power/Knowledge and Its Relevance for Human Resource Management. Academy of Management Review 18(3), 518-545 (1993)

34. Von Krogh, G.: Care in Knowledge Creation. California Management Review 40(3), 133$153(1998)$

35. Warf, B., Grimes, J.: Counterhegemonic Discourses on the Internet. The Geographical Review 87(2), 256-274 (1997)

36. Wasko, M., Faraj, S.: It Is What One Does: Why People Participate and Help Others in Electronic Communities of Practice. Journal of Strategic Information Systems 9(2-3), 155$173(2000)$

37. World Bank, http: / / www . worldbank. org

38. World Bank. World Development Report: Knowledge for Development, Washington D.C. (1998) 